\title{
Sazonalidade de Haematobia irritans no Brasil Central ${ }^{1}$
}

\author{
Ivo Bianchin ${ }^{2}$, Wilson W. Koller ${ }^{2}$ e Edenio Detmann ${ }^{3}$
}

\begin{abstract}
Bianchin I., Koller W.W. \& Detmann E. 2006. [The seasonality of Haematobia irritans in central Brazil.] Sazonalidade de Haematobia irritans no Brasil Central. Pesquisa Veterinária Brasileira 26(2):79-86. Área de Sanidade Animal, Embrapa Gado de Corte, Cx. Postal 154, Campo Grande, MS 79002-970, Brazil. E-mail: bianchin@cnpgc.embrapa.br

Horn fly (Haematobia irritans) is one of the most important Brazilian cattle ectoparasites. Epidemiological studies are needed due the increasing difficulty of their chemical control. In order to obtain a better knowledge of their seasonal population dynamics, 14 days interval fly counts were made on 7-30 month old beef cattle, from winter 1996 to summer 2002. Horn fly population levels increase $(\mathrm{P}<0.05)$ was observed during the seasons of each infestation period (spring until autumn), mainly in spring and summer, and sometimes in autumn, followed by a significant reduction $(\mathrm{P}<0.05)$ in winter, when the relative humidity decreases to less than $60 \%$. A straight $(\mathrm{P}<0.05)$ and immediate correlation between the relative humidity and the fly count was found, whilst the most evident effects of temperature and rain fall $(\mathrm{P}<0.05)$ were associated with counts done $42-56$ days after attainment of the climatic data. The highest parasitism load (average number of flies per animal) observed for the genetic groups used were: Aberdeen Angus x Nellore = 173.5 (134-254); $1 / 2$ Brown Swiss x Nellore = 183.5 (32-540); 3/4 Aberdeen Angus x Nellore $=133.0(18-374)$, and Valdostana $x$ Nellore $=219.0(58-620)$. Torrential rain falls during the initial half of the infestation period (spring until midsummer) are common in this region and were considered the main reason for the low to moderate population levels verified at that time, in comparison with those which occurred during the last half of the infestation period.
\end{abstract}

INDEX TERMS: Horn fly, epidemiology, population dynamics, ectoparasites, cattle.

RESUMO.- A mosca-dos-chifres (Haematobia irritans) é um dos principais ectoparasitos de bovinos no Brasil. Estudos epidemiológicos são exigidos devido às dificuldades crescentes do seu controle químico. Por isso, para um melhor conhecimento da dinâmica populacional sazonal desta mosca foram realizadas contagens a cada 14 dias sobre bovinos para corte, entre 7 e 30 meses de idade, durante o período de inverno de 1996 até o verão de 2002. Foi verificada elevação nos níveis populacionais de $H$. irritans $(\mathrm{P}<0,05)$, entre as estações de cada período de infestação (primavera até o outono), especialmente na primavera e verão e, às vezes, no outono, seguida de uma queda significativa $(P<0,05)$ no inverno, quando a umidade relativa alcançou níveis inferiores a $60 \%$. Houve uma relação direta e imediata na contagem de moscas com a variação da umidade relativa $(\mathrm{P}<0,05)$ enquanto que os

\footnotetext{
${ }^{1}$ Recebido em 4 de julho de 2005.

Aceito para publicação em 10 de novembro de 2005 .

2 Área de Sanidade Animal, Embrapa Gado de Corte, BR 262 Km 4, Caixa Postal 154, Campo Grande, MS 79002-970, Brasil. *Autor para correspondência. E-mail: bianchin@cnpgc.embrapa.br

${ }^{3}$ Departamento de Zootecnia, Universidade Federal de Viçosa, 36571000 Viçosa, MG, Brasil.
}

efeitos mais evidentes da temperatura e a precipitação pluviométrica estiveram associados com contagens feitas 42 a 56 dias depois da leitura desses dados climáticos $(\mathrm{P}<0,05)$. As cargas parasitárias mais elevadas (número médio de moscas por animal) por grupo genético estudado foram: Aberdeen Angus $\mathrm{x}$ Nelore $=$ 173,5 (134-254); 1⁄2 Pardo Suíço x Nelore = 183,5 (32-540); 3/4 Aberdeen Angus x Nelore $=133,0$ (18-374) e, Valdostana $x$ Nelore $=219,0(58-620)$. A ocorrência de chuvas torrenciais durante a metade inicial do período de infestação (primavera até meados do verão), comum na região deste estudo, foi considerada a principal responsável pelos níveis populacionais variando de moderados a baixos verificados nesta época em comparação àqueles verificados no restante do período.

TERMOS DE INDEXAÇÃO: Mosca-dos-chifres, epidemiologia, dinâmica populacional, ectoparasitos, bovinos.

\section{INTRODUÇÃO}

A mosca-dos-chifres, Haematobia irritans (L.) é um ectoparasito que se alimenta exclusivamente de sangue do hospedeiro, preferencialmente bovinos, e cujo ciclo biológico ocorre nas fezes do mesmo. Este inseto se dispersou em todo território brasileiro, 
nas regiões favoráveis ao seu desenvolvimento e, inclusive, em outros países sul-americanos (Mendes \& Linhares 1999). O dano que lhe é atribuído com respeito à pecuária no Brasil foi estimado em US\$ 150 milhões anuais (Grisi et al. 2002). Recentemente, Bianchin et al. (2004) determinaram que essa perda era de $10 \%$ no ganho de peso vivo dos animais, o que representaria uma arroba a menos de carne ao abate. Com base no abate anual projetado no Anualpec (2004) de 19,4 milhões de fêmeas e 21,9 milhões de machos, e o preço médio das respectivas arrobas no país ( $\mathrm{R} \$ 55,00$ e R\$ 60,00 para fêmeas e machos, respectivamente), este prejuízo seria, atualmente, de R\$ 2,38 bilhões. Considerando-se a cotação atual do dólar em $\mathrm{R} \$ 2,75$, então a estimativa desse prejuízo passa a ser de US\$ 865 milhões. Este prejuízo é semelhante ao apontado há pouco mais de uma década por Kunz et al. (1991), nos Estados Unidos, que foi estimado em US\$ 876 milhões. Além disso, as picadas da mosca deixam marcas no couro do hospedeiro, que implicam em despesas para serem removidas, pelo processo denominado "maquiagem" (Silva et al. 2002). $O$ custo desse processo não foi quantificado.

O sucesso no controle populacional de qualquer organismo está diretamente associado ao domínio do conhecimento de sua epidemiologia. A bioecologia da praga de interesse e de outros organismos a ela associados tais como vetores e/ou inimigos naturais, constitui ferramenta de valor indiscutível para a tomada de decisões quanto à época do ano e/ou estádio de desenvolvimento da praga oportunos para a adoção de medidas de controle populacional. Também oferece boas referências na escolha de pesticidas e/ou concentrações mais indicadas com vistas ao menor impacto sobre o ambiente, redução de resíduos tóxicos nos alimentos produzidos e/ou com possível efeito sobre os organismos biocontroladores presentes. Nesses aspectos, a sua dinâmica populacional e/ou sazonalidade ainda necessitam de estudos específicos em diversas regiões do Brasil, devido à carência de informações quanto ao comportamento deste inseto em diversas regiões pecuárias, bem como, da relação "parasito $\mathrm{x}$ hospedeiro" em função da diversidade de raças e/ou grupos genéticos atualmente empregados.

A padronização de metodologia nesses estudos é um dos pontos importantes para permitir a comparação de informações entre as distintas regiões brasileiras. Por exemplo, verificou-se haver influência do ciclo circadiano na distribuição das moscas sobre os hospedeiros, sendo que estas tendem a se agrupar nas regiões ventral e lateral dos animais durante as horas mais quentes do dia (Schreiber \& Campbell 1986). Estes autores também observaram que nas primeiras horas da manhã, informação corroborada por Lima et al. (2002), e nas últimas da tarde, as moscas permanecem em maior número na região escapular, cernelha e laterais, onde são mais facilmente visualizadas durante as contagens. Assim, o método empregado e/ou a hora em que a contagem é realizada, por se tratar de amostragem relativa, pode determinar o grau de precisão da mesma.

Este trabalho teve por objetivo determinar o comportamento epidemiológico e/ou sazonal da mosca-dos-chifres, considerando a atual intensificação do sistema de produção pelo uso de animais de diferentes raças ou cruzamentos, criados com a finalidade de redução da idade de abate e melhoria da qualidade da carne produzida.

\section{MATERIAL E MÉTODOS}

O presente estudo foi conduzido na Fazenda Experimental da Empresa Brasileira de Pesquisa Agropecuária - Embrapa Gado de Corte, em Campo Grande, MS. O clima da região situa-se na faixa de transição entre o Cfa mesotérmico úmido sem estiagem e o subtipo AW (clima tropical de savana) com estação chuvosa no verão e seca no inverno. As chuvas são freqüientes e pesadas no período chuvoso e quente (outubro a abril) e escassas e leves no período seco e mais frio (maio a setembro), situação esta semelhante a cerca de $65 \%$ do território brasileiro. A temperatura média dos meses mais frios está acima de $17^{\circ} \mathrm{C}$ e nos meses mais quentes a média mensal está em torno de $25^{\circ} \mathrm{C}$ (Ometto 1981). Os dados climáticos foram fornecidos pela Estação Climatológica Principal do Ministério da Agricultura, Pecuária e Abastecimento (MAPA), situada na Embrapa Gado de Corte, em Campo Grande, MS.

Foram avaliados três ciclos experimentais de 2 anos cada, utilizando-se 16 bovinos machos por ciclo. Todos os animais foram vacinados contra carbúnculo sintomático e febre aftosa, bem como, orquiectomizados, segundo a rotina de manejo da Embrapa Gado de Corte, e receberam suplementação protéica na estação seca do ano nos meses de junho a outubro. Houve variação, entre ciclos, com respeito à raça dos animais experimentais, utilizando-se aqueles disponíveis no início de cada ciclo, quando haviam completado sete meses de idade, assim que desmamados. Ao final de cada um destes ciclos, ao atingirem a idade de 30 meses, os animais estavam terminados e eram encaminhados ao abate. Esta foi a razão da duração bianual de cada ciclo.

No primeiro ciclo (1996-1998) foram utilizados oito bezerros mestiços $3 / 4$ Aberdeen Angus x Nelore e oito 1/2 Pardo Suíço x Nelore. No segundo ciclo (1998-2000) os 16 bovinos utilizados foram $3 / 4$ Aberdeen Angus x Nelore, e no terceiro ciclo (2000-2002), foram 16 Valdostana x Nelore. A cada ciclo os animais foram distribuídos em dois piquetes formados com Brachiaria brizantha cv. Marandu, com quatro hectares cada um. A taxa de lotação média durante o período experimental foi fixada em 1,0 UA/ha e os animais não receberam nenhum tratamento químico contra parasitos.

Para a contagem dos níveis de infestação pela mosca-dos-chifres, e de modo a racionalizar o manejo e evitar o estresse, metade dos animais foi conduzida ao mangueiro em intervalos de 14 dias e, todos, a cada 28 dias, em função de outras atividades de manejo a que foram submetidos. As contagens foram realizadas nos animais quando imobilizados no tronco do mangueiro e o número de moscas contado de um lado de cada animal, multiplicando-se o valor obtido por dois (Bianchin \& Alves 2002). As contagens estiveram ao encargo sempre da mesma pessoa, previamente treinada para essa atividade, e foram realizadas entre as $8 \mathrm{~h} 00$ e $10 \mathrm{~h} 00$, horário no qual as moscas tendem a ocupar as laterais e dorso dos hospedeiros (Schreiber \& Campbell 1986, Lima et al. 2002). Durante as contagens, as paredes laterais dos troncos de contenção foram abertas apenas na metade superior, mantendo-se, assim, no escuro a região ventral dos animais. Tal procedimento contribuiu para que as moscas se deslocassem para a parte superior do hospedeiro, permitindo uma melhor visualização das mesmas, ao contrário do que geralmente acontece quando os animais estão livres no campo.

Os valores obtidos para a contagem de moscas por animal foram transformados por intermédio do logaritmo de base neperiana, reduzidos para média em função das estações do ano e analisados de forma multivariada em esquema de medidas repetidas no tempo (Littlell et al. 1998). Para o ciclo I foram avaliadas as hipóteses de coincidência, horizontalidade e paralelismo entre os perfis temporais dos diferentes grupos genéticos (Harris 1975). Para os ciclos II e III, por se utilizarem cada um de apenas um grupo genético, somente a 
hipótese de horizontalidade foi avaliada. Como elemento auxiliar para a avaliação de horizontalidade empregou-se a análise de perfil, segundo descrições de Curi (1980). Os dados do último outono de cada ciclo não foram utilizados na parte inicial das análises (Quadros 2 a 5), porque as medidas repetidas no tempo exigem que todos os animais apresentem todas as informações da primeira até a última contagem, contudo, isso não foi possível porque alguns animais ficaram prontos e foram abatidos antes disso. $O$ programa empregado nas análises foi SAS (1989), o "Statistical Analysis System".

Posteriormente, as associações entre o número de moscas por animal e os parâmetros climáticos, tais como a temperatura média diária $\left({ }^{\circ} \mathrm{C}\right)$, a precipitação pluviométrica $(\mathrm{mm} / \mathrm{dia})$ e a umidade relativa (UR) do ar (\%) foram quantificadas, em cada ciclo de avaliação, por intermédio da correlação linear de Pearson (Steel et al. 1997) em esquema serial. Nessa situação, as associações entre as contagens de moscas e os parâmetros climáticos foram quantificadas com as medidas tomadas no dia da avaliação, denominada correlação serial de "ordem 0"; com as medidas climáticas tomadas na avaliação anterior, denominada correlação serial de "ordem 1"; com as medidas climáticas tomadas na segunda avaliação anterior, denominada correlação serial de "ordem 2", e assim sucessivamente até alcançarse a correlação serial de "ordem 10". Para todos os procedimentos estatísticos adotou-se $\alpha=0,05$.

Na representação gráfica da dinâmica populacional da moscados-chifres foi utilizado o número médio de moscas por bovino por data de contagem. Quanto aos dados climáticos considerados, utilizouse o total acumulado no período entre as contagens (14 dias precedentes) para a precipitação, e os valores médios para temperatura média e a umidade relativa.

\section{RESULTADOS E DISCUSSÃO}

O comportamento estacional das variáveis climáticas avaliadas durante o período de estudo é apresentado no Quadro 1. Verifi-

Quadro 1. Estimativas dos valores médios de variáveis climáticas em função das estações do ano, em Campo Grande, MS

\begin{tabular}{|c|c|c|c|c|}
\hline \multirow[t]{2}{*}{ Ano } & \multirow[t]{2}{*}{ Estação } & \multicolumn{3}{|c|}{ Variável } \\
\hline & & $\begin{array}{l}\text { Precipitação } \\
\text { (mm/dia) }\end{array}$ & $\begin{array}{c}\text { Temperatura } \\
\left({ }^{\circ} \mathrm{C}\right)\end{array}$ & $\begin{array}{c}\text { Umidade } \\
(\%)\end{array}$ \\
\hline \multirow[t]{2}{*}{1996} & Inverno & 1,26 & 21,03 & 60,19 \\
\hline & Primavera & 3,69 & 24,58 & 73,64 \\
\hline \multirow[t]{4}{*}{1997} & Verão & 6,91 & 24,75 & 79,07 \\
\hline & Outono & 3,45 & 21,37 & 73,46 \\
\hline & Inverno & 0,67 & 22,53 & 59,34 \\
\hline & Primavera & 6,75 & 25,53 & 72,93 \\
\hline \multirow[t]{4}{*}{1998} & Verão & 4,54 & 26,06 & 78,63 \\
\hline & Outono & 4,50 & 21,64 & 77,27 \\
\hline & Inverno & 2,52 & 21,77 & 70,14 \\
\hline & Primavera & 3,80 & 24,24 & 72,87 \\
\hline \multirow[t]{4}{*}{1999} & Verão & 6,08 & 24,98 & 79,99 \\
\hline & Outono & 1,21 & 21,55 & 65,89 \\
\hline & Inverno & 0,89 & 22,49 & 52,74 \\
\hline & Primavera & 4,47 & 24,90 & 61,23 \\
\hline \multirow[t]{4}{*}{2000} & Verão & 7,13 & 25,13 & 79,46 \\
\hline & Outono & 1,30 & 22,03 & 70,04 \\
\hline & Inverno & 2,78 & 20,86 & 64,21 \\
\hline & Primavera & 4,62 & 24,57 & 69,70 \\
\hline \multirow[t]{4}{*}{2001} & Verão & 6,29 & 25,12 & 78,33 \\
\hline & Outono & 2,85 & 22,06 & 71,35 \\
\hline & Inverno & 1,48 & 21,83 & 56,51 \\
\hline & Primavera & 7,47 & 24,38 & 72,92 \\
\hline 2002 & Verão & 4,94 & 25,24 & 74,20 \\
\hline
\end{tabular}

cou-se por análise descritiva, que nos seis anos considerados (inverno de 1996 até o verão de 2002), os maiores índices de precipitação, por período de infestação da mosca-dos-chifres (setembro a maio), foram registrados durante quatro verãos (1997, 1999, 2000, 2001) e durante duas primaveras (1997 e 2001). A umidade relativa (UR) independente dos índices de precipitação foi sempre mais alta durante o verão do que na primavera e registrou os menores valores no inverno. No outono de 1997 e de 2001 a UR registrada ficou muito próxima dos valores observados para a primavera anterior; foi mais alta nos anos de 1998 e 2000, e esta relação só se mostrou favorável à primavera anterior no ano de 1999, em função de um inverno chuvoso e da antecipação do período de chuvas (Fig.1).

As temperaturas médias mais baixas por estação ocorreram no outono e inverno, diferindo, no geral, menos de $1,5^{\circ} \mathrm{C}$ entre si. A diferença entre a temperatura média entre primavera e verão, no geral, foi ainda menor, ao redor de $1,0^{\circ} \mathrm{C}$. Entre os períodos outono + inverno e primavera + verão, no entanto, verificou-se, no geral, o acréscimo de até $3,5^{\circ} \mathrm{C}$ na temperatura média em favor das duas últimas estações (Fig.1). O período mais quente e chuvoso do ano, reportado na literatura como o mais favorável ao desenvolvimento da mosca-dos-chifres (Saueressig et al. 1995, Lima et al. 1999, Barros 2001, Bianchin \& Alves 2002), estaria, portanto, representado pela primavera e o verão. Com base nos resultados obtidos, sugere-se que a inclusão do outono, pelo menos em sua metade inicial, feita pelos autores acima, como período favorável ao desenvolvimento da mosca, se deve em função da UR do ar e da umidade no solo requerida pelo inseto, resultantes do excedente hídrico, no geral presente nesse período do ano na região do Brasil Central.

No Quadro 2 é apresentado o resumo dos resultados obtidos nos Quadros 3, 4 e 5. Constatou-se, para o primeiro ciclo, que não houve influência $(P>0,05)$ do grupo genético estudado quanto à carga parasitária observada, ou seja, a infestação não diferiu entre o grupo $3 / 4$ Aberdeen Angus x Nelore e o grupo 1/2 Pardo Suíço x Nelore. A análise entre o conjunto de grupos genéticos não foi feita, evidentemente, porque as observações foram realizadas em anos (ciclos) distintos. Entretanto, verificaram-se diferenças $(\mathrm{P}<0,05)$ na infestação entre as estações do ano, portanto sazonais, para todos os ciclos avaliados.

De modo geral, verificaram-se elevações no número de moscas $(\mathrm{P}<0,05)$, para todos os ciclos, nas estações com temperatura média mais elevada (Quadros 3, 4 e 5, Fig.1), especialmente no verão. No outono, apesar do decréscimo da temperatura e da precipitação (Quadro 1, Fig.1), verificou-se que a carga parasitária não diferiu em relação ao verão $(P>0,05)$, em uma ocasião (Quadro 3), porém aumentou em duas (Quadros 4 e 5). Conforme proposto anteriormente, é provável que isso ocorra, pois nesse período ainda há influência positiva da umidade no solo, a qual é devida ao superávit acumulado no balanço hídrico, que por sua vez também está intimamente relacionado aos valores moderados a altos da umidade relativa ainda presentes no outono (Quadro 1).

Os resultados acima conferem parcialmente, no que se refere à dinâmica de ocorrência, com aqueles disponíveis para a região do Brasil Central. No Pantanal sul-mato-grossense, entre junho de 1993 e maio de 1995, Barros (2001) verificou um com- 

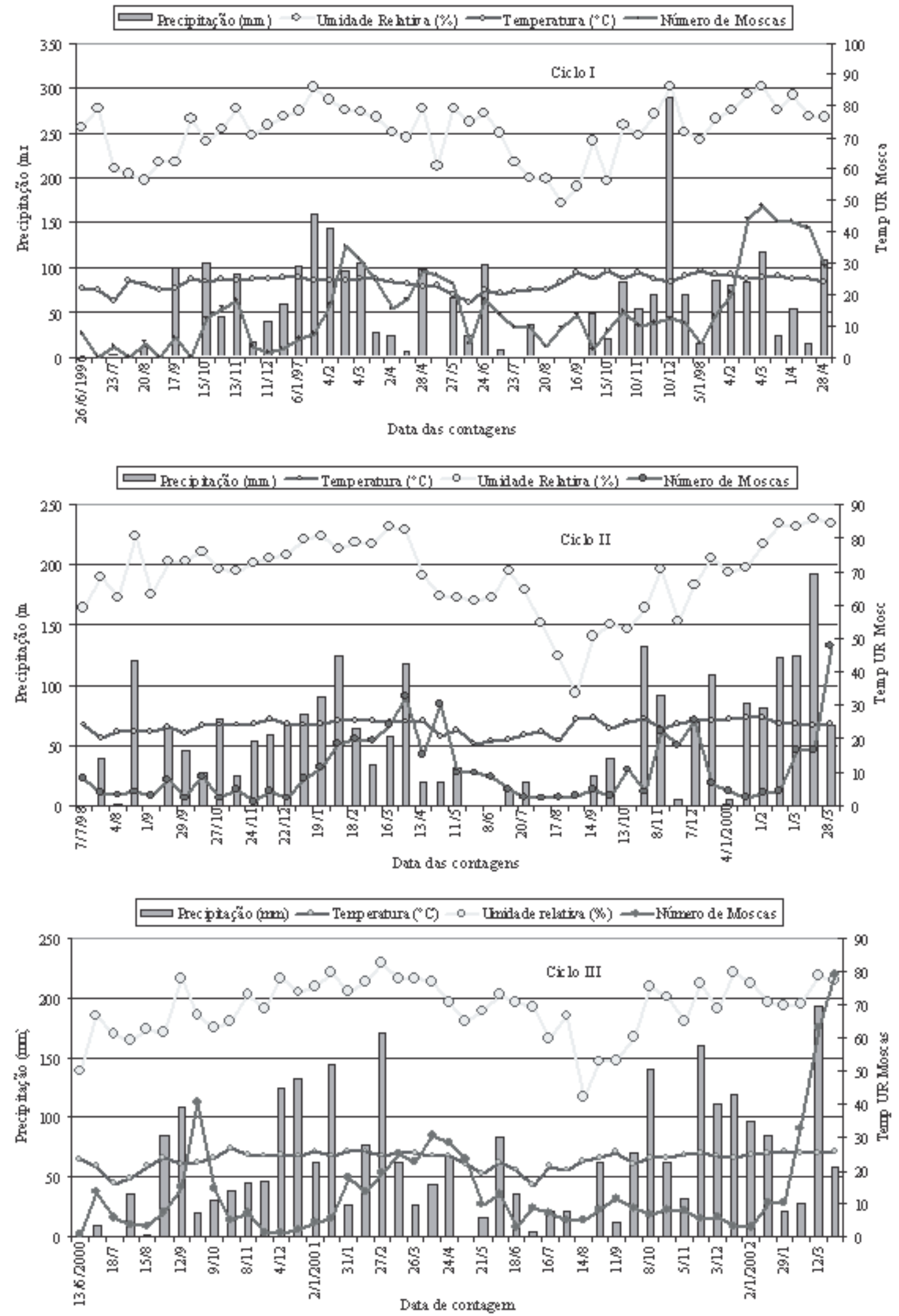

Fig.1. Dinâmica populacional da mosca Haematobia irritans e dados climáticos em Campo Grande, MS. 
Quadro 2. Níveis descritivos de probabilidade para o erro tipo I associados às diferentes hipóteses de nulidade empregadas na avaliação da variável logaritmo natural do número de moscas por animal em função dos diferentes ciclos de avaliação (Ciclo I: jun.1996 a mar.1998; Ciclo II: jun.1998 a mar.2000; Ciclo III: jun.2000 a mar.2002), em Campo Grande, MS

\begin{tabular}{cccc}
\hline Ciclo & \multicolumn{3}{c}{ Hipótese } \\
\cline { 2 - 4 } & Horizontalidade $^{\mathrm{a}}$ & Coincidência $^{\mathrm{b}}$ & Paralelismo $^{\mathrm{c}}$ \\
\hline I & 0,0003 & 0,1018 & 0,2513 \\
II & $<0,0001$ & - & - \\
III & $<0,0001$ & - & -
\end{tabular}

${ }^{\mathrm{a} A}$ hipótese de horizontalidade entre perfis temporais refere-se à avaliação de alterações globais entre os diferentes momentos de avaliação.

${ }^{\mathrm{b}} \mathrm{A}$ hipótese de coincidência refere-se à avaliação de diferenças entre grupos genéticos diferentes (somente Ciclo I).

${ }^{\mathrm{C}} \mathrm{A}$ hipótese de Paralelismo refere-se à avaliação de interações entre os momentos de avaliação e os grupos genéticos avaliados (somente Ciclo I).

Quadro 3. Valores médios absolutos e diferenciais do logaritmo natural do número de moscas por animal em função dos diferentes momentos ou estações de avaliação para o Ciclo I, em Campo Grande, MS

\begin{tabular}{cccc}
\hline $\begin{array}{c}\text { Momento de } \\
\text { avaliação }^{\text {a }}\end{array}$ & $\begin{array}{c}\text { Valor Médio } \\
(\exp (\ln Y))\end{array}$ & $\begin{array}{c}\text { Valor Médio } \\
(\operatorname{lnY})\end{array}$ & $\begin{array}{c}\text { Valor Diferencial } \\
\text { Médio }^{\text {b }}\end{array}$ \\
\hline Inverno 1996 & 14,31 & 2,6613 & - \\
Primavera 1996 & 29,63 & 3,3887 & $+0,7274^{*}$ \\
Verão 1997 & 55,35 & 4,0137 & $+0,6250^{*}$ \\
Outono 1997 & 58,77 & 4,0736 & $+0,0599^{\text {ns }}$ \\
Inverno 1997 & 28,41 & 3,3468 & $-0,7268^{*}$ \\
Primavera 1997 & 23,16 & 3,1431 & $-0,2037^{\text {ns }}$ \\
Verão 1998 & 60,33 & 4,0998 & $+0,9567^{*}$
\end{tabular}

anverno: 22.06- 21.09; Primavera: 22.09- 21.12,;Verão: 22.12- 21.03; Outono: 22.03- 21.06.

${ }^{b}$ ns e $^{*}=$ Não-significativo e significativo em nível de $5 \%$ de probabilidade, respectivamente, segundo a análise de perfil.

Quadro 4. Valores médios absolutos e diferenciais do logaritmo natural do número de moscas por animal em função dos diferentes momentos ou estações de avaliação para o Ciclo II, em Campo Grande, MS

\begin{tabular}{cccc}
\hline $\begin{array}{c}\text { Momento de } \\
\text { avaliação }^{\text {a }}\end{array}$ & $\begin{array}{c}\text { Valor Médio } \\
(\exp (\operatorname{lnY}))\end{array}$ & $\begin{array}{c}\text { Valor Médio } \\
(\operatorname{lnY})\end{array}$ & $\begin{array}{c}\text { Valor Diferencial } \\
\text { Médio }^{\text {b }}\end{array}$ \\
\hline Inverno 1998 & 8,40 & 2,1279 & - \\
Primavera 1998 & 8,66 & 2,1585 & $+0,0306^{\text {ns }}$ \\
Verão 1999 & 35,25 & 3,5625 & $+1,4040^{*}$ \\
Outono 1999 & 48,17 & 3,8748 & $+0,3123^{*}$ \\
Inverno 1999 & 6,62 & 1,8900 & $-1,9848^{*}$ \\
Primavera/1999 & 31,71 & 3,4567 & $+1,5667^{*}$ \\
Verão/2000 & 36,12 & 3,5869 & $+0,1302^{\text {ns }}$
\end{tabular}

anverno: 22.06-21.09; Primavera: 22.09-21.12; Verão: 22.12-21.03; Outono: 22.03-21.06.

${ }^{b} \mathrm{~ns} \mathrm{e}^{*}=$ Não-significativo e significativo em nível de $5 \%$ de probabilidade, respectivamente, segundo a análise de perfil.

portamento bimodal na dinâmica populacional de Haematobia irritans e os picos de ocorrência aconteceram durante a estação chuvosa, entre meados da primavera até meados de outono. Em Campo Grande, MS, entre novembro de 1991 e maio de 1995 , Bianchin \& Alves (2002) verificaram que a infestação média de moscas por animal (vacas e bezerros), entre outubro a maio ou, eventualmente, até junho, não passou de 80 . Trabalho similar ao anterior foi realizado no Distrito Federal por Saueressig et al. (1995) que observaram entre junho de 1994 e março de 1995 , infestação média mensal nunca superior a 40 moscas por animal. A infestação máxima individual foi de 184 moscas. Em

Quadro 5. Valores médios absolutos e diferenciais do logaritmo natural do número de moscas por animal em função dos diferentes momentos ou estações de avaliação para o Ciclo III, em Campo Grande, MS

\begin{tabular}{cccc}
\hline $\begin{array}{c}\text { Momento de } \\
\text { avaliação }^{\mathrm{a}}\end{array}$ & $\begin{array}{c}\text { Valor Médio } \\
(\exp (\ln Y))\end{array}$ & $\begin{array}{c}\text { Valor Médio } \\
\operatorname{lnY})\end{array}$ & $\begin{array}{c}\text { Valor Diferencial } \\
\text { Médio }^{\mathrm{b}}\end{array}$ \\
\hline $\begin{array}{c}\text { Inverno/2000 } \\
\text { Primavera/2000 }\end{array}$ & 11,47 & 2,4399 & - \\
Verão/2001 & 31,58 & 3,0716 & $+0,6317^{*}$ \\
Outono/2001 & 41,77 & 3,4021 & $+0,3305^{*}$ \\
Inverno/2001 & 17,90 & 3,7321 & $+0,3300^{*}$ \\
Primavera/2001 & 16,47 & 2,8847 & $-0,8474^{*}$ \\
Verão/2002 & 74,34 & 4,3086 & $-0,0833^{\text {ns }}$ \\
\hline
\end{tabular}

anverno: 22.06-21.09; Primavera: 22.09-21.12; Verão: 22.12-21.03; Outono: 22.03-21.06.

${ }^{b} \mathrm{~ns} \mathrm{e}^{*}=$ Não-significativo e significativo em nível de $5 \%$ de probabilidade, respectivamente, segundo a análise de perfil.

Quadro 6. Estimativas para as correlações lineares de Pearson em esquema serial para as associações entre o número médio de moscas por animal e os valores de variáveis climáticas tomados ao momento de cada avaliação durante o Ciclo I, em Campo Grande, MS

\begin{tabular}{|c|c|c|c|}
\hline \multirow[t]{2}{*}{ Ordem $^{a}$} & \multicolumn{3}{|c|}{ Variável $^{\text {b }}$} \\
\hline & $\begin{array}{c}\text { Precipitação } \\
\text { (mm/dia) }\end{array}$ & $\begin{array}{c}\text { Temperatura } \\
\left({ }^{\circ} \mathrm{C}\right)\end{array}$ & $\begin{array}{c}\text { Umidade } \\
\text { Relativa (\%) }\end{array}$ \\
\hline \multirow[t]{2}{*}{0} & 0,1705 & 0,1841 & 0,4982 \\
\hline & 0,2627 & 0,2260 & 0,0005 \\
\hline \multirow[t]{2}{*}{1} & 0,1559 & 0,2292 & 0,4739 \\
\hline & 0,3122 & 0,1344 & 0,0011 \\
\hline \multirow[t]{2}{*}{2} & 0,2619 & 0,2878 & 0,4913 \\
\hline & 0,0937 & 0,0644 & 0,0009 \\
\hline \multirow[t]{2}{*}{3} & 0,1850 & 0,4455 & 0,3588 \\
\hline & 0,2468 & 0,0035 & 0,0211 \\
\hline \multirow[t]{2}{*}{4} & 0,3317 & 0,4520 & 0,4171 \\
\hline & 0,0340 & 0,0030 & 0,0066 \\
\hline \multirow[t]{2}{*}{5} & 0,3858 & 0,5260 & 0,4189 \\
\hline & 0,0138 & 0,0005 & 0,0071 \\
\hline \multirow[t]{2}{*}{6} & 0,4191 & 0,4985 & 0,4491 \\
\hline & 0,0078 & 0,0012 & 0,0041 \\
\hline \multirow[t]{2}{*}{7} & 0,4152 & 0,4873 & 0,4383 \\
\hline & 0,0094 & 0,0019 & 0,0058 \\
\hline \multirow[t]{2}{*}{8} & 0,4114 & 0,4639 & 0,4314 \\
\hline & 0,0113 & 0,0038 & 0,0076 \\
\hline \multirow[t]{2}{*}{9} & 0,4862 & 0,4068 & 0,4693 \\
\hline & 0,0026 & 0,0137 & 0,0038 \\
\hline \multirow[t]{2}{*}{10} & 0,5100 & 0,3721 & 0,4979 \\
\hline & 0,0017 & 0,0275 & 0,0023 \\
\hline
\end{tabular}

aordem: $0=$ Dia da contagem de moscas; $1=14$ dias antes de $0 ; 2=28$ dias antes de $0 ; 3=42$ dias antes de $0 ; 4=56$ dias antes de $0 ; \ldots ; 10=$ 140 dias antes de 0.

bos valores subscritos referem-se aos níveis descritivos de probabilidade para o erro tipo I associados à não-rejeição da hipótese de nulidade $\left(\mathrm{H}_{0}\right.$ : $\left.\mathrm{r}=0 ; \mathrm{H}_{\mathrm{a}}: \mathrm{r}^{1} 0\right)$. 
Araçatuba, SP, Lima et al. (1999) verificaram maior incidência de moscas de setembro a maio, positivamente associada $(\mathrm{P}<0,05)$ com as variações de temperatura e os índices pluviométricos. A média mensal máxima do número de moscas por animal foi 97,1. Nos estudos desta região foram utilizados animais da raça Nelore, que apresentaram, no geral, conforme os relatos acima, cargas parasitárias médias bem inferiores àquelas verificadas nos animais deste estudo, pertencentes a raças de procedência européia (Bos taurus) ou de cruzamentos destas com a raça Nelore (Bos indicus).

Em Roraima, onde o inverno é chuvoso e a seca ocorre no verão, Collares (1990) também observou um comportamento bimodal na dinâmica populacional de Haematobia irritans semelhante àquele descrito por Barros (2001) para a região do Pantanal sul-mato-grossense.

Uma possível explicação para os baixos níveis populacionais verificados durante o período de maior precipitação pluviométrica, meados de primavera e verão (Fig.1), também comentada por Barros (2001), foi apontada por Hughes (1979), que atribui a ação de chuvas torrenciais na destruição das massas fecais em que as moscas se desenvolvem. Na região deste estudo chuvas torrenciais são relativamente freqüientes durante a primavera e o verão, porém no outono são menos freqüentes e, no geral, com menor intensidade pluviométrica. A par da destruição do

Quadro 7. Estimativas para as correlações lineares de Pearson em esquema serial para as associações entre o número médio

de moscas por animal e os valores de variáveis climáticas

tomados ao momento de cada avaliação durante o Ciclo II, em Campo Grande, MS

\begin{tabular}{|c|c|c|c|}
\hline \multirow[t]{2}{*}{ Ordem $^{a}$} & \multicolumn{3}{|c|}{ Variável $^{\mathrm{b}}$} \\
\hline & $\begin{array}{c}\text { Precipitação } \\
\text { (mm/dia) }\end{array}$ & $\begin{array}{c}\text { Temperatura } \\
\left({ }^{\circ} \mathrm{C}\right)\end{array}$ & $\begin{array}{c}\text { Umidade } \\
\text { Relativa (\%) }\end{array}$ \\
\hline \multirow[t]{2}{*}{0} & 0,2306 & 0,1593 & 0,3573 \\
\hline & 0,1274 & 0,2957 & 0,0159 \\
\hline \multirow[t]{2}{*}{1} & 0,4881 & 0,2657 & 0,3731 \\
\hline & 0,0008 & 0,0812 & 0,0125 \\
\hline \multirow[t]{2}{*}{2} & 0,5319 & 0,3774 & 0,4491 \\
\hline & 0,0002 & 0,0125 & 0,0025 \\
\hline \multirow[t]{2}{*}{3} & 0,4788 & 0,4263 & 0,3415 \\
\hline & 0,0013 & 0,0048 & 0,0267 \\
\hline \multirow[t]{2}{*}{4} & 0,3081 & 0,5005 & 0,2845 \\
\hline & 0,0499 & 0,0008 & 0,0712 \\
\hline \multirow[t]{2}{*}{5} & 0,2587 & 0,5173 & 0,1332 \\
\hline & 0,1067 & 0,0006 & 0,4125 \\
\hline \multirow[t]{2}{*}{6} & 0,1294 & 0,4033 & 0,0935 \\
\hline & 0,4323 & 0,0108 & 0,5710 \\
\hline \multirow[t]{2}{*}{7} & 0,1549 & 0,3048 & 0,0319 \\
\hline & 0,3529 & 0,0626 & 0,8493 \\
\hline \multirow[t]{2}{*}{8} & 0,1139 & 0,1233 & 0,0802 \\
\hline & 0,5021 & 0,4670 & 0,6371 \\
\hline \multirow[t]{2}{*}{9} & $-0,0385$ & 0,0420 & 0,0195 \\
\hline & 0,8237 & 0,8078 & 0,9103 \\
\hline \multirow[t]{2}{*}{10} & 0,1376 & $-0,0362$ & 0,1494 \\
\hline & 0,4304 & 0,8362 & 0,3914 \\
\hline
\end{tabular}

ardem: $0=$ Dia da contagem de moscas; $1=14$ dias antes de $0 ; 2=28$ dias antes de $0 ; 3=42$ dias antes de $0 ; 4=56$ dias antes de $0 ; \ldots ; 10=$ 140 dias antes de 0.

${ }^{b}$ Os valores subscritos referem-se aos níveis descritivos de probabilidade para o erro tipo I associados à não-rejeição da hipótese de nulidade $\left(\mathrm{H}_{0}\right.$ : $\left.r=0 ; H_{a}: r^{1} 0\right)$.
Quadro 8. Estimativas para as correlações lineares de Pearson em esquema serial para as associações entre o número médio de moscas por animal e os valores de variáveis climáticas tomados ao momento de cada avaliação durante o Ciclo III, em Campo Grande, MS

\begin{tabular}{|c|c|c|c|}
\hline \multirow[t]{2}{*}{ Ordem $^{a}$} & \multicolumn{3}{|c|}{ Variável $^{\text {b }}$} \\
\hline & $\begin{array}{c}\text { Precipitação } \\
\text { (mm/dia) }\end{array}$ & $\begin{array}{c}\text { Temperatura } \\
\left({ }^{\circ} \mathrm{C}\right)\end{array}$ & $\begin{array}{c}\text { Umidade } \\
\text { relativa }(\%)\end{array}$ \\
\hline \multirow[t]{2}{*}{0} & 0,0991 & 0,2263 & 0,2865 \\
\hline & 0,5124 & 0,1303 & 0,0534 \\
\hline \multirow[t]{2}{*}{1} & 0,2516 & 0,2652 & 0,2963 \\
\hline & 0,0954 & 0,0782 & 0,0479 \\
\hline \multirow[t]{2}{*}{2} & $-0,0321$ & 0,3324 & 0,1746 \\
\hline & 0,8362 & 0,0274 & 0,2562 \\
\hline \multirow[t]{2}{*}{3} & 0,0674 & 0,2555 & 0,2069 \\
\hline & 0,6676 & 0,0980 & 0,1830 \\
\hline \multirow[t]{2}{*}{4} & 0,2981 & 0,1189 & 0,2929 \\
\hline & 0,0550 & 0,4533 & 0,0596 \\
\hline \multirow[t]{2}{*}{5} & 0,2824 & 0,0823 & 0,3075 \\
\hline & 0,0735 & 0,6088 & 0,0503 \\
\hline \multirow[t]{2}{*}{6} & 0,3558 & 0,2072 & 0,3150 \\
\hline & 0,0241 & 0,1994 & 0,0475 \\
\hline \multirow[t]{2}{*}{7} & 0,3897 & 0,3384 & 0,1659 \\
\hline & 0,0141 & 0,0349 & 0,3127 \\
\hline \multirow[t]{2}{*}{8} & 0,3515 & 0,3393 & 0,2334 \\
\hline & 0,0303 & 0,0370 & 0,1583 \\
\hline \multirow[t]{2}{*}{9} & 0,1757 & 0,3141 & 0,1926 \\
\hline & 0,2980 & 0,0581 & 0,2532 \\
\hline \multirow[t]{2}{*}{10} & 0,3904 & 0,2573 & 0,2151 \\
\hline & 0,0184 & 0,1296 & 0,2076 \\
\hline
\end{tabular}

ardem: $0=$ Dia da contagem de moscas; $1=14$ dias antes de $0 ; 2=28$ dias antes de $0 ; 3=42$ dias antes de $0 ; 4=56$ dias antes de $0 ; \ldots ; 10=$ 140 dias antes de 0.

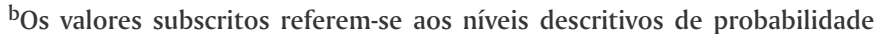
para o erro tipo $\mathrm{I}$ associados à não-rejeição da hipótese de nulidade $\left(\mathrm{H}_{0}\right.$ : $\left.r=0 ; H_{a}: r^{1} 0\right)$.

substrato alimentar pela chuva foi observado por Jones \& Kunz (1996) que a sobrevivência dos estádios imaturos da mosca (larva e pupa) é prejudicada quando estes são expostos à imersão, situação esta que também ocorre em função das já mencionadas chuvas torrenciais.

Quedas significativas $(\mathrm{P}<0,05)$ nos níveis populacionais da mosca ocorreram durante os invernos dos anos de 1997, 1999 e 2001 (Quadros 3, 4 e 5), portanto, no segundo ano de avaliação de cada ciclo. Nos demais invernos essa informação não foi possível, pois coincidiu com o início das contagens e, portanto, não havia contagens da estação anterior para servir de referência sobre a evolução da dinâmica populacional. A diferença climática básica observada entre o inverno e outono, que poderia explicar a redução dos níveis populacionais entre ambas, foi na umidade relativa média (Quadro 1), sempre em torno de 13-15\% inferior no inverno, e que no inverno destes anos alcançou valores inferiores a $60 \%$.

O número de moscas por animal nos picos de ocorrência pode ter variado, entre outros fatores já discutidos, em função do grupo genético avaliado nos ciclos, bem como, com o aumento da idade dos animais, mas apenas este último fator pode ser inferido a partir dos números abaixo apresentados. Uma análise específica não foi conduzida sobre estas questões, pois não fizeram parte do objetivo deste trabalho, porém, aumentos 
da carga parasitária foram relatados na literatura, tanto em função da idade do animal (Bianchin et al. 2004), quanto do tamanho do hospedeiro (Steelman et al. 1996). A redução da idade de abate, que vem sendo obtida através de melhoramentos genéticos e da nutrição, está contribuindo para abreviar o tempo de exposição do hospedeiro ao parasito e seus efeitos.

Observando a Figura 1 verificou-se a existência, em diversas ocasiões, de mais de dois picos populacionais da mosca por período de infestação. Os relatos de Bianchin \& Alves (2002), Pruett et al. (2003) e Jensen et al. (2004) de que a carga parasitária individual mantém uma proporcionalidade com a dinâmica populacional do restante do rebanho foram também aqui corroborados.

Tal comportamento, estudado por Jensen et al. (2004), resultou na proposição de que deve haver semioquímicos voláteis envolvidos tanto na atração, quanto na repelência das moscas, que seriam característicos a cada animal e que, em razão disso, a carga parasitária média de $H$. irritans em um rebanho é diretamente influenciada pela proporção de animais suscetíveis. Estas informações revelam novas possibilidades de investigação com vistas à seleção de indivíduos resistentes ao parasito, aos mecanismos de repelência envolvidos, e reforçam também a necessidade de levar esses aspectos em consideração nos estudos sobre níveis de parasitismo, agrupando os animais segundo o grau de suscetibilidade. Neste particular, Jensen et al. (2004) verificaram que mantendo um animal suscetível junto com quatro resistentes o número médio de moscas diminuiu em todos os animais, entretanto, ao colocar um animal resistente junto com quatro suscetíveis, a carga parasitária individual aumentou.

No Quadro 6 (Ciclo I) é apresentada a relação entre os níveis populacionais e os fatores climáticos avaliados em diferentes ocasiões (data da contagem; data da contagem anterior; data da segunda contagem anterior... até a décima contagem anterior). Conforme mencionado anteriormente, não houve análise em separado para grupo genético, pois o objetivo exclusivo foi o estudo da dinâmica populacional sazonal da mosca. Observa-se que as correlações significativas $(\mathrm{P}<0,05)$ entre o número de moscas, a precipitação, a temperatura e a UR do ar foram as de número 4,3 e zero, respectivamente, com destaque para a UR do ar. Como resultado concluiu-se que a variação entre contagens do número de $H$. irritans, em uma dada estação do ano, está mais diretamente influenciada pelas condições momentâneas de UR do ar, do que da precipitação e temperatura, mesmo porque esta última varia relativamente pouco dentro de cada estação. A precipitação e a temperatura média apresentaram uma correlação mais forte $(\mathrm{P}<0,05)$ sobre contagens subseqüentes, mais precisamente, na terceira e/ou quarta data posterior ao registro dos dados climáticos. Desta forma, sugere-se que estes dois fatores climáticos têm maior influência sobre as gerações posteriores àquelas avaliadas durante as contagens, afetando o potencial de produção de descendentes e/ou o sucesso de desenvolvimento desta descendência. As informações acima, no geral, também se repetiram nos Quadros 7 e 8, respectivamente, ciclos II e III, podendo, também, serem observadas, em uma visualização geral na Fig.1, o que reforça as conclusões retiradas.
Tendo em vista que a mosca-dos-chifres pode apresentar até 19,1 gerações anuais e que durante o período do ano favorável ao seu desenvolvimento a duração do seu ciclo biológico varia de duas a três semanas (Rodrigues \& Marchini 2001), sugere-se que o intervalo de contagens para novos estudos da dinâmica populacional de $H$. irritans seja semanal. Esta sugestão pode, ainda, ser reforçada pelo fato de que durante o período favorável ao desenvolvimento do parasito, o mesmo se encontra presente nos diversos estádios de desenvolvimento e na forma adulta, o que implica em constantes sobreposições de gerações, de modo que contagens com intervalo longo podem não registrar a real intensidade dos picos e/ou parte deles. Considerando que a carga parasitária individual varia muito, segundo mencionado por Bianchin \& Alves (2002), Pruett et al. (2003) e Jensen et al. (2004), é recomendável que o número de bovinos empregados por tratamento seja suficiente para poder, posteriormente, para efeito da análise dos dados, agrupar os animais segundo os níveis "altamente" "moderadamente" e "pouco" infestados. Isso implica, em função do grau de dificuldade e trabalho envolvido, em agir com parcimônia quanto ao número de grupos genéticos ou de tratamentos a serem empregados em cada experimento.

No período de temperaturas mais baixas, e seco do ano, no geral de maio a setembro na região do Brasil Central, foram aqui observados baixos níveis de ocorrência da mosca, corroborando com os relatos de Saueressig et al. (1995), Lima et al. (1999), Barros (2001) e Bianchin \& Alves (2002). Nesse período adverso ao desenvolvimento do inseto, segundo Mendes \& Linhares (1999), ocorre diapausa em parte das pupas produzidas. Estes autores, no Estado de São Paulo, verificaram 7,7\% de diapausa em pupas durante junho e julho de 1993 e 9,9\% entre maio e julho de 1994.

Supõe-se que na região Sul do Brasil, devido ao fato do clima temperado local apresentar temperaturas médias mais baixas do que no Brasil Central, a diapausa em pupas também deve ocorrer regularmente e, talvez, durante maior número de meses, bem como, em maior percentual de indivíduos do que nas condições que incluem as demais regiões brasileiras. Tal suposição baseia-se na dinâmica populacional observada por AlvesBranco et al. (1997) e Martins et al. (2002), que registraram infestações nulas ou próximas a zero durante o período de inverno.

Estudos realizados sobre a dinâmica populacional desta mosca, em Bagé, na região de Campanha do Rio Grande do Sul, no período de setembro de 1994 até setembro de 1996, apresentaram uma infestação média mensal máxima de 63,8 moscas por animal em março, e um segundo pico de ocorrência em novembro (57,6 moscas) (Alves-Branco et al. 1997). Neste estudo, a carga parasitária máxima por animal em bovinos Hereford foi de 163 moscas. Assim, a carga parasitária observada naquele local, em função da raça utilizada mostrou-se próxima àquelas registradas para a raça Nelore na região do Brasil Central. No segundo estudo, em São Gabriel, região Centro-Oeste do Estado, Martins et al. (2002) observaram, entre outubro de 1998 e julho de 2000, a ocorrência de quatro picos populacionais de pequena intensidade no primeiro ano de estudo e três no segundo, registrados entre dezembro e maio. Os picos com maiores níveis populacionais ocorreram em março de 2000 (149 mos- 
cas) e maio de 1999 (91,5 moscas), sendo Aberdeen Angus e Devon as raças bovinas estudadas. O relato destes últimos autores corrobora com as informações obtidas, e quanto à literatura específica, de que raças de procedência européia Bos taurus (puras ou cruzadas) apresentam, no geral, infestações superiores àquelas apresentadas por animais da raça $B$. indicus. No presente estudo conclui-se que o cruzamento entre $B$. taurus e $B$. indicus pode determinar maior carga parasitária de $H$. irritans nos descendentes produzidos do que aquela verificada em animais com predominância de sangue Nelore.

\section{REFERÊNCIAS}

Alves-Branco F.P.J., Pinheiro A.C. \& Sapper M.F.M. 1997. Epidemiologia da Haematobia irritans na região da Campanha do RS. Dados preliminares. $10^{\circ}$ Sem. Bras. Parasitol. Vet., Itapema, SC, p.46. (Resumo)

Anualpec 2004. FNP Consultoria de Agroinformativos, São Paulo, p.66-70.

Barros A.T.M. 2001. Dynamics of Haematobia irritans irritans (Diptera: Muscidae) infestation on Nellore cattle in the Pantanal, Brazil. Mem. Inst. Oswaldo Cruz 96(4):445-450.

Bianchin I. \& Alves R.G.O. 2002. Mosca-dos-chifres, Haematobia irritans: comportamento e danos em vacas e bezerros Nelore antes da desmama. Pesq. Vet. Bras. 22(3):109-113.

Bianchin I., Koller W.W. \& Alves R.G.O. 2004. Efeito da mosca-dos-chifres, Haematobia irritans (L.) (Diptera: Muscidae), no ganho de peso de bovinos Nelore. Ciencia Rural, Santa Maria, 34(3):885-890.

Collares N.P.C. 1990. Biologia da Haematobia irritans em Roraima. Dissertação de Mestrado, Universidade Federal de Minas Gerais, Belo Horizonte. $57 \mathrm{p}$.

Curi P.R. 1980. Análises de medidas repetidas em experimentos biológicos. Revta Bras. Estat. 41(161):137-150.

Grisi L., Massard C.L., Moya Borja G.E. \& Pereira J.B. 2002. Impacto econômico das principais ectoparasitoses em bovinos no Brasil. Hora Vet., Porto Alegre, 21(125):8-10.

Harris R.J. 1975. A primer of multivariate statistics. Academic Press, New York. 332p.

Hughes R.D. 1979. Rainfall as a cause of mortality in a dung breeding fly. J. Aust. Entomol. Soc. 18:323-327.

Jensen K.M.V., Jespersen J.B., Birkett M.A., Pickett J.A., Thomas G., Wadhams L.J. \& Woodcock C.M. 2004. Variation in the load of the horn fly, Haematobia irritans, in cattle herds is determined by the presence or absence of individual heifers. Med. Vet. Entomol. 18:275-280.

Jones S.R. \& Kunz S.E. 1996. Effects of immersion in water on survival of preimaginal stages of Haematobia irritans (Diptera, Muscidae). J. Med. Entomol. 33:27-31.
Kunz S.E., Murrel K.D., Lambert G., James L.F. \& Terrill C.E. 1991. Estimated losses of livestock to pests, p.69-98. In Pimentel D. (ed.) CRC Handbook of Pest Management in Agriculture. Vol.1, CRC, Boca Raton.

Lima L.G.F., Perri S.H.V. \& Prado A.P. 1999. Densidade populacional da mosca-dos-chifres (Haematobia irritans irritans) em bovinos da raça Nelore (Bos indicus) no município de Araçatuba, SP. 11을. Bem. Bras. Paratol. Vet., Salvador, BA, p.122. (Resumo)

Lima L.G.F., Prado A.P. \& Perri S.H.V. 2002. Localização preferencial e índices diferenciados de infestação da mosca-dos-chifres (Haematobia irritans) em bovinos da raça Nelore. Pesq. Vet. Bras. 22(1):25-32.

Littlell R.C., Henry P.R. \& Ammerman C.B. 1998. Statistical analysis of repeated measures data using SAS procedures. J. Anim. Sci. 76(5):12161231.

Martins J.R., Porciúncula J.A. \& Vieira M.I.B. 2002. Dinâmica populacional da mosca-dos-chifres, Haematobia irritans (Diptera: Muscidae), em São Gabriel, Região Centro-Oeste do Rio Grande do Sul. Revta Bras. Parasitol. Vet. 11(2):99-101.

Mendes J. \& Linhares A.X. 1999. Diapause, pupation sites and parasitism of the horn fly, Haematobia irritans, in south-eastern Brazil. Med. Vet. Entomol. 13:185-190.

Ometto J.C. 1981. Bioclimatologia Vegetal. Editora Agronômica Ceres, São Paulo. 425p.

Pruett J.H., Steelman C.D., Miller J.A., Pound J.M. \& George J.E. 2003. Distribution of horn flies on individual cows as a percentage of the total horn fly population. Vet. Parasitol. 116(3):251-258.

Rodrigues S.R. \& Marchini L.C. 2001. Estudo de temperaturas em massas fecais de bovinos e previsão do número de gerações anuais de Haematobia irritans (Diptera, Muscidae), em Piracicaba, SP, Brasil. Revta Bras. Entomol. 45(2): 89-94.

SAS Institute. 1989. User's Guide: statistics. Cary. 943p.

Saueressig T.M., Salviano A., Barcellos A.O. \& Bianchin I. 1995. Dinâmica populacional da mosca-dos-chifres, Haematobia irritans, e seu efeito no ganho de peso de bovinos na região do Distrito Federal. $9^{\circ}$ Semin. Bras. Parasitol. Vet., Campo Grande, MS, p.31. (Resumo)

Schreiber E.T. \& Campbell J.B. 1986. Horn fly (Diptera: Muscidae) distribution on cattle as influenced by host color and time of day. Environ. Entomol. 22(1):25-32.

Silva L.V., De La Rue M.L. \& Graça D.L. 2002. Lesão da mosca-dos-chifres (Haematobia irritans Linnaeus, 1758) na pele de bovinos e impacto na indústria de couro. Ciência Rural, Santa Maria, 32(6):1039-1043.

Steel R.G.D., Torrie J.H. \& Dickey D.A. 1997. Principles and Procedures of Statistics. A biometrical approach. 3rd ed. McGraw Hill, New York. $666 \mathrm{p}$.

Steelman C.D., Brown C.J., McNew R.W., Gbur E.E., Brown M.A. \& Tolley G. 1996. The effects of selection of size in cattle on horn fly population density. Med. Vet. Entomol. 10(2):129-136. 